\title{
Situation actuelle des maladies à transmission vectorielle communes au Canada
}

\author{
Lindsay $\mathrm{LR}^{1 *}$
}

\author{
Affiliation \\ ${ }^{1}$ Laboratoire national de microbiologie, Agence de la santé publique du Canada, Winnipeg (Manitoba) \\ *Correspondance : robbin.lindsay@phac-aspc.gc.ca
}

Citation proposée : Lindsay LR. Situation actuelle des maladies à transmission vectorielle communes au Canada. Relevé des maladies transmissibles au Canada 2016;42:223-4. https://doi.org/10.14745/ccdr.v42i10a03f

\section{Contexte}

À quelques exceptions près, par exemple le paludisme dans le sud de l'Ontario dans les années 1800, les maladies à transmission vectorielle sont relativement rares au Canada. Toutefois, ces dernières années, le virus du Nil occidental et la maladie de Lyme ont émergé en tant que préoccupations importantes en matière de santé publique dans de nombreuses parties du Canada.

\section{Objectif}

Résumer les facteurs qui favorisent l'émergence du virus du Nil occidental et de la maladie de Lyme, et décrire les méthodes de surveillance utilisées actuellement pour évaluer le risque général d'exposition humaine.

\section{Narratif}

Les principaux facteurs qui favorisent l'émergence des maladies à transmission vectorielle au Canada sont l'augmentation des précipitations, la hausse des températures et la disponibilité accrue d'hôtes. À ce jour, le Canada a eu la chance de ne pas avoir de transmission par les moustiques du virus de la dengue, du virus Zika ou du virus Chikungunya à l'échelle locale étant donné que le climat est trop froid pour que les principaux vecteurs, les moustiques Aedes aegypti et Aedes albopictus, y survivent.

Le virus du Nil occidental, qui est principalement transmis par les moustiques Culex (1) est la maladie transmise par les moustiques la plus commune au Canada. Les oiseaux sont des hôtes amplificateurs, car ils augmentent la présence et la répartition du virus du Nil occidental dans l'environnement. Par le passé, la surveillance se basait sur la collecte et l'analyse d'oiseaux morts; à l'heure actuelle, le mécanisme de surveillance principal comprend la collecte et l'analyse de moustiques. La surveillance des moustiques est relativement coûteuse et peut faire l'objet de restrictions budgétaires lorsque le chiffre annuel des cas de virus du Nil occidental est faible. Toutefois, dans des conditions environnementales appropriées, d'importantes éclosions du virus du Nil occidental ont eu lieu après de nombreuses années d'activité virale limitée. Par conséquent, le maintien d'une capacité de surveillance adéquate pour définir le risque relatif au virus du Nil occidental représente un défi important dans de nombreuses compétences canadiennes.

La maladie de Lyme est la maladie transmise par les tiques la plus commune au Canada, et les vecteurs sont les tiques aux pattes noires (lxodes scapularis) qu'on trouve dans les parties sud du Manitoba, de l'Ontario, du Québec, de la Nouvelle-Écosse et du Nouveau-Brunswick et les tiques Ixodes pacificus qu'on trouve en Colombie-Britannique $(2,3)$. La surveillance visant à mieux définir le risque d'exposition humaine aux tiques infectées repose sur l'évaluation du risque environnemental (c.-à-d. sur la définition des endroits où les populations de tiques aux pattes noires prédominent). Le taux des populations de tiques aux pattes noires dans l'est et le centre du Canada est si importante depuis les quinze dernières années que la méthode relativement simple de l'échantillonnage au filet traînant (passer un tissu sur le sol de façon systématique pour recueillir des échantillons de tiques cherchant un hôte) a remplacé la méthode plus exigeante en main-d'œuvre de collecte et d'analyse de petits hôtes mammifères. De plus, la maladie de Lyme est devenue une maladie à déclaration obligatoire à l'échelle nationale en 2009 afin que l'épidémiologie de la maladie puisse être plus clairement définie et examinée au fil du temps.

Le nombre de cas de maladie de Lyme déclarés a augmenté de façon exponentielle ces cinq dernières années, et un certain nombre de zones urbaines sont désormais touchées. L'un des défis les plus importants est de sensibiliser les professionnels de la santé aux zones où se trouvent des tiques aux pattes noires infectées, qui sont en constante expansion, et de s'assurer que les patients reçoivent rapidement un diagnostic et un traitement approprié. Contrairement au virus du Nil occidental, le dépistage de la maladie de Lyme n'est pas assez sensible aux premières étapes de la maladie; toutefois, des travaux sont en cours pour améliorer la précision des tests diagnostiques (4).

L'épidémiologie du virus du Nil occidental et celle de la maladie de Lyme au Canada sont très différentes. Le virus du Nil occidental suit un schéma d'expansion et de récession avec des éclosions souvent suivies par de nombreuses années où on enregistre peu d'infections humaines. Les cas de maladie de Lyme sont bien plus constants et augmentent chaque année, en partie en raison de l'expansion de l'aire des vecteurs tiques. 


\section{Conclusion}

On sait que le virus du Nil occidental et la maladie de Lyme touchent les populations des milieux urbains. Il est essentiel de maintenir des programmes de surveillance efficaces pour comprendre les dynamiques du risque pour les humains et de mesurer l'efficacité des stratégies de prévention des maladies pour réduire au minimum l'incidence de ces agents pathogènes sur la santé des Canadiens.

\section{Conflit d'intérêts}

Aucun.

\section{Références}

1. Zheng $\mathrm{H}$, Drebot MA, Coulthart MB. Le virus du Nil occidental au Canada : un virus en évolution permanente, mais présent pour de bon. Relevé des maladies transmissibles au Canada 2014;40-10:199-204. http://www. phac-aspc.gc.ca/publicat/ccdr-rmtc/14vol40/dr-rm40-10/drrm40-10-comm-fra.php.

2. Ogden NH, Koffi JK, Pelcat Y, Lindsay LR. Risque environnemental pour la maladie de Lyme dans l'est et le centre du Canada : un sommaire d'informations récentes en matière de surveillance. Relevé des maladies transmissibles au Canada 2014;40-5:77-86. http://www.phac-aspc.gc.ca/ publicat/ccdr-rmtc/14vol40/dr-rm40-05/dr-rm40-05-1-fra. php.

3. Hatchette TF, Johnston BL, Schleihauf E, Mask A, Haldane D, Drebot M, Baikie M, Cole TJ, Fleming S, Gould R, Lindsay R. Epidemiology of Lyme disease, Nova Scotia, Canada, 20022013. Emerg Infect Dis. 2015;21(10):1751-8.

4. Lindsay LR, Bernat K, Dibernardo A. Diagnostic en laboratoire de la maladie de Lyme. Relevé des maladies transmissibles au 2014;40:209-14. http://www.phac-aspc. gc.ca/publicat/ccdr-rmtc/14vol40/dr-rm40-11/dr-rm40-11lyme-2-fra.php.
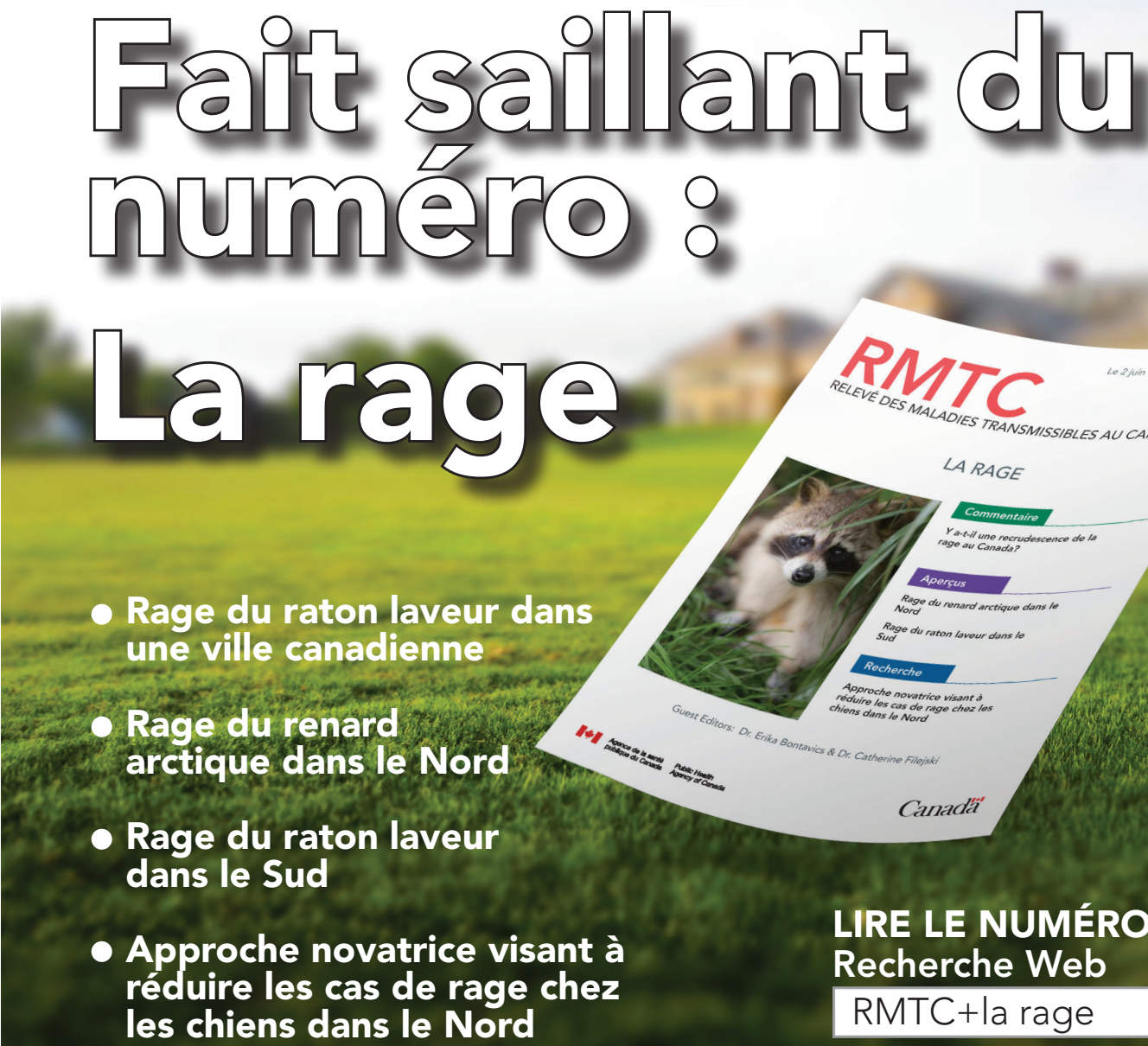